\title{
ÉTICA E VIRTUDE: A FORMAÇÃO HUMANA NA ESCOLA
}

\author{
Mateus de Freitas Barreiro ${ }^{1}$, Alonso Bezerra de Carvalho ${ }^{2}$
}

Universidade Estadual Paulista - UNESP, ${ }^{1}$ Pós-Graduação em Educação, Marília, SP. CNPq. ${ }^{2}$ Departamento de Educação, Assis, SP e Programa de Pós-Graduação em Educação, Marília, SP. E-mail: mateusfbb@bol.com.br. Conselho Nacional de Desenvolvimento Científico e Tecnológico.

\section{RESUMO}

Este artigo visa investigar a ética na filosofia de Aristóteles, através da elucidação da virtude, afim de compreender como ocorre a formação humana na escola atual. A ética não se limita apenas a um sistema conceitual filosófico sobre como se orientar com base em perpetuação de valores morais, mas antes de tudo, a ética é um hábito que constitui o sujeito para orientar ações que visem o bem dos outros e da equidade coletiva. Concluímos que os problemas escolares devem abranger tanto a dimensão ética como a epistêmica. Contudo em virtude da dificuldade em concretizar esses objetivos na escola, os alunos têm sido cada vez mais encaminhados pelos educadores aos profissionais da saúde, na qual a prática da normalização por meio da medicalização, vem cada vez mais substituindo a responsabilidade ética de diversos agentes dentro e fora da escola.

Palavras-chave: Aristóteles, formação humana e escola.

\section{ETHICS AND VIRTUDE: THE HUMAN FORMATION IN SCHOOL}

\section{ABSTRACT}

This article aims to investigate the ethics of Aristotle's philosophy, through the elucidation of virtue in order to understand how does the human formation in the current school. Ethics is not just limited to a philosophical conceptual system on how to steer based on the perpetuation of moral values, but above all, ethics is a habit which is the subject to guide actions aimed at the good of others and collective equity. We conclude that school problems should cover both the ethical dimension as epistemic. However due to the difficulty in achieving these goals in school, students have been increasingly forwarded by educators to health professionals, in which the practice of standardization through medicalization, is increasingly replacing the ethical responsibility of different actors within and out of school.

Keywords: Aristótle, human formation and school.

\section{INTRODUÇÃO}

É importante ensinar os fundamentos das chamadas ciências duras, como a matemática, a física e a química, para formar os alunos em seu pensamento lógico e científico. Contudo, para a construção da formação humana dos alunos não se pode descartar, em nossa visão, o ensino das ciências humanas, e especialmente da filosofia, pois é preciso formar indivíduos éticos e que se preocupem com a sua comunidade. São vários os textos de Aristóteles, assim como de outros filósofos gregos, que podem oferecer contribuições importantes para repensar problemas da sociedade contemporânea. Aristóteles, foi pesquisador, filósofo e precursor de numerosas ciências, teve também seu lado educador, pois além de ter sido professor, foi também fundador de uma escola - o Liceu. Desta forma, acreditamos que se justifica neste artigo, a nossa preocupação em relacionar a filosofia com a educação, ainda que, tenhamos que nos restringir ao entendimento dos conceitos de ética e virtude, articulados ao contexto social contemporâneo da escola.

Nas obras de Aristóteles pode-se constatar que a ética possui um caráter interligado à realidade empírica da pólis, onde essa noção se relaciona com a política, ética e educação. Dessa forma a escolha de Aristóteles entre os filósofos da Grécia antiga, é relevante 
para trabalhar o campo da educação sob uma perspectiva de formação ética que possibilite avaliar as circunstâncias de cada situação concreta que envolve uma ação. Cabe destacar, que a democracia na Grécia antiga, visava exercitar a autonomia do indivíduo por meio da participação direta nos assuntos das cidades, enquanto na democracia moderna, quem decide é aquele representa os cidadãos. É importante pensar que na democracia atual, a ciência, a tecnologia e até mesmo a educação, podem estar relacionadas as produções de riquezas e na manutenção de poder do Estado. Sabe-se que a valorizações de um determinado tipo conhecimento, é relativo a cada contexto cultural. Enquanto os Gregos valorizam a questão da formação integral do indivíduo, incluindo o âmbito ético, político e estético, atualmente estas preocupações foram deixadas de lado, em detrimento da supervalorização da produção de riquezas por meio da racionalidade instrumental. Mas é preciso reiterar que a formação humana (paidéia), é uma unidade originária em que a ideia de formação é entendida como algo global, na qual se distingue das diversas concepções educacionais dos modernos que se direcionam na especialização da produção do conhecimento em diversos segmentos.

\section{METODOLOGIA}

A bibliografia para fundamentar teoricamente o objeto de estudo, será norteada pelos pressupostos filosóficos de Aristóteles e comentadores que nos permitam avaliar as contribuições da que a ética e a virtude tem na construção de um diálogo que possibilite entender como a ética e a virtude contribuem para da formação humana na escola contemporânea, pois é preciso repensar novas formas de se relacionar eticamente com o outro que é diferente de si. Ao trazer Aristóteles para atualidade, fica evidente o carácter diacrônico da pesquisa, fazendo-se necessário contextualizar a época em que viveu Aristóteles, e utilizar autores que nos possibilitem fazer esta passagem para entender a escola na sociedade contemporânea, tendo em vista que o conceito de ética e virtude se modifica nas práticas e significados sociais.

\section{RESULTADOS}

$\mathrm{Na}$ atualidade há uma dificuldade em categorizar as emoções como objetos científicos, o que advém uma dimensão de ser humano eminentemente racional. Atualmente, as emoções não são vistas na sala de aula como um elemento inerente ao ser humano, mas como algo anormal, que deve ser diagnosticado ${ }^{1}$. A representação de que a razão sirva para afastar os desvios perniciosos das emoções, é um olhar dual que também foi fortalecido na filosofia moderna com Descartes, por meio da cisão entre corpo e mente. As concepções patológicas sobre as emoções parecem perpetuar até os dias de hoje nas ciências médicas e na educação. Porém, a partir da perspectiva aristotélica e de outros pensadores, é possível problematizar os discursos a respeito psicopatologia através do campo da ética, pois as emoções podem também podem ser pensadas não apenas como algo eminentemente negativo ou uma virtude em si mesma, mas ela está inserida em uma relação com o outro, e representa a diferença interiorizada entre nós e esse outro.

\section{DISCUSSÃO}

A compreensão aristotélica das emoções no contexto da sala de aula, pressupõe um modo de pensar distinto dos pensamentos hegemônicos atuais em que o aluno precisa ser supostamente curado ou até excluído. O conflito do aluno categorizado como aquele que possivelmente deve ser curado ou excluído, poderá canalizado e refletido em conjunto com os agentes da escola, pois as emoções não são consideradas boas ou ruins em sua essência, mas tornam-se prejudiciais quando não são submetidas pelo crivo da razão. Inclusive, a reflexão das emoções pode implicar em um exercício ético, tendo em vista que na filosofia aristotélica, o homem não nasce virtuoso, mas torna-se virtuoso através do ensino e prática de hábitos que são incorporados, o que emana a noção de ética e autonomia para a educação.

A ideia de formação humana (paidéia) esteve sempre presente na filosofia prática de Aristóteles, que era acima tudo, um modo de ultrapassar a concepção de transmissão de conhecimentos voltados para uma aptidão

\footnotetext{
${ }^{1}$ A psicopatologia é concebida como uma ciência que tem por objetivo fornecer uma compreensão descritiva dos fenômenos, das formas anormais de experiência e conduta (SONENREICH et al, 1999, p.6). É evidente que a área da psicopatologia apresenta diferentes visões sobre o homem e o conhecimento, que implica em discussões sobre fundamentos epistemológicos e científicos da psicopatologia. A tentativa mais conhecida para superar os impasses gerados pelas inúmeras abordagens da psicopatologia tem como o seu principal representante o DSM-IV (Manual de Diagnóstico e Estatística da Associação Psiquiátrica Americana), que visa propor uma definição empírica e pragmática das entidades nosográficas (CECCARELLI, 2003, p.17).
} 
específica, e que pode ser útil para repensar a atual crise ética que privilegia apenas os saberes especializados. É certo que o ideal de formação ética aristotélico, não deva ser tomado como um modelo a ser implantado, mas a partir das tensões e reflexões entre temáticas amplas como filosofia de Aristóteles e as práticas atuais de educação, é possível caminhar por temáticas pouco exploradas, mas que podem proporcionar contribuições para o desenvolvimento de práticas pedagógicas que visem formar um indivíduo ético e virtuoso.

No livro I, Aristóteles irá problematizar a virtude que é uma excelência da alma, deste modo, primeiramente é preciso investigar o que é a alma ${ }^{2}$. Aristóteles sustenta que a alma, é dividida em duas partes, uma é a parte a racional e a outra e privada de razão. Essas partes são distintas como as partes do corpo, mas inseparáveis por natureza. Parece ter também na alma, a outra parte irracional que, porém, que é presente na razão (ARISTÓTELES, 2012, p.29). A parte irracional se divide em duas partes, há uma parte vegetativa e a desiderativa, que é a aquela que pode obedecer à razão. Estes princípios irracionais e racionais são distintos, porém, são interdependentes já que um princípio interfere no outro.

Em relação à interdependência dos aspectos racionais e irracionais, pode ser aludida a definição aristotélica de comportamento acrático. Para Burnyeat, o homem acrático possui um desejo de fazer determinada coisa, mas sob a influência de um desejo oposto, acaba fazendo outra (BURNYEAT, 2010, p.175). Embora possa ocorrer uma espécie de sabotagem das ações por aspectos emocionais, comentadores como Irwin, sustentam que há certa estabilidade nas consecuções das ações quando o indivíduo é virtuoso. Segundo Irwin (2010), na filosofia aristotélica, a pessoa virtuosa que detém objetivos rígidos não sabota seus próprios fins, porque há um valor dominante que expressa seu estado de caráter geral. Quando a pessoa cultiva estados estáveis da virtude é possível assegurar a felicidade, enquanto a pessoa viciosa é instável (IRWIN, 2010, p.231-232). Desse modo, as afeções da alma são instáveis nos indivíduos acráticos, mas são estáveis em indivíduos virtuosos. É justamente na diferenciação das

\footnotetext{
2 “Entendemos por virtude humana não a do corpo, mas a da alma; e também dizemos que a felicidade é uma atividade da alma" (ARISTÓTELES, 2012, p.28).
}

partes da alma que Aristóteles iniciara o desenvolvimento do conceito de virtude.

No início do livro II, Aristóteles trata de duas espécies de virtude, a saber, a intelectual e a moral. As duas partes da virtude são intrínsecas a alma que também contém dois direcionamentos. No livro II de EN, Aristóteles define a virtude da seguinte forma: "a virtude é, então, uma disposição de caráter relacionada com a escolha de ações e paixões, e consiste num mediana, isto é, a mediana relativa a nós, que é determinada por um princípio racional próprio do homem dotado de sabedoria prática" (ARISTÓTELES, 2012, p.40).

O hábito é o que orienta as ações virtuosas, pois as duas espécies de virtude, a intelectual e a moral, não são inatas ou existentes a priori, mas são desenvolvidas pela disposição e hábito. Para Aristóteles a virtude intelectual, se deve em grande parte, da sua geração e crescimento ao ensino, que é preciso experiência e tempo, enquanto a virtude moral do hábito, cujo nome é oriundo de pequena modificação desta palavra, do grego: ethos, e a sua derivação ethiké. (ARISTÓTELES, 2012, p.31). A virtude intelectual tem a relação com a aprendizagem no âmbito da razão, por isso é preciso experiência e tempo, enquanto a virtude moral (ético) é um hábito, em que o indivíduo precisa praticar sucessivamente ações éticas, como um costume ou exercício.

Sobre a responsabilidade ética agente para desenvolvimento da virtude, McDowell (2010) concebe a deliberação em Aristóteles, como um processo de pensamento que é presente antes do agir, de modo que podemos entender a ação. A questão da deliberação também é elucidada por MacDowell ao relacionar - que Aristóteles entende por escolha (prohairesis) que é resultado de uma deliberação. (MCDOWELL, 2010, p.245). É preciso acrescentar que a discussão sobre as virtudes e a responsabilidade na conduta ética do agente, ao trazer em Aristóteles a noção de voluntariedade (to hekousion), que é um raciocínio que tem uma finalidade (telos), enquanto a prohairesis é o exercício do caráter. Fica claro, na concepção de homem aristotélica, há elementos emocionais que afetam a razão e, por conseguinte, as escolhas virtuosas.

Embora os indivíduos virtuosos utilizem a reta da razão para avaliar as manifestações das emoções nas escolhas, na óptica da filosofia aristotélica, os aspectos racionais e emocionais 
são consonantes, já que a noção de autonomia e o papel que a razão desempenha nas escolhas, são fundamentais, porém, não são absolutos. Tal panorama pressupõe que a educação não é apenas um processo racional e deliberativo, tendo em vista que a apreensão do conhecimento e o desenvolvimento da ética para o desenvolvimento da virtude são permeados pelos aspectos involuntários. Dessa forma, por força do hábito e do ensino, a deliberação agrega os aspectos que são desenvolvidos por meio das virtudes intelectuais e morais, porém para o desenvolvimento da virtude é preciso que exista relações entre os cidadãos.

A necessidade do outro como elemento avaliativo das ações, é o que possibilita formar um cidadão ético e participante da comunidade política, mas de fato, a mediação de outrem, é o que possibilita a reciprocidade e por entender a si mesmo. A noção de subjetividade concebida pelos Gregos é uma noção diferente para os modernos, a consciência do si é formada através do outro, já que o "eu" não é unificado, constituindo um "campo aberto de forças ${ }^{3}$. Essa concepção dos Gregos para se conhecer a si mesmo por meio do outro, também diz respeito às reflexões sobre a aquisição do conhecimento, porque $\mathrm{o}$ ensino tende a ser comumente concebido como uma didática fechada que sempre segue passos pré-estabelecidos, em que limitaria as possibilidades de interação do aluno como um agente participativo do conhecimento.

\section{CONCLUSÃO}

No presente artigo, foi possível repensar as contribuições dos conceitos de ética e virtude como possibilidade de formar um cidadão que utilize o espaço escolar para repensar novas formas de relacionar com o outro que é diferente de si e faz parte de diferentes contextos culturais. A virtude aristotélica foi analisada, enquanto um conceito imanente à noção de ética. A importância de refletir sobre ética, diz respeito a um sujeito autônomo, que poderá deliberar e escolher as ações a serem realizadas. Repensar a filosofia de Aristóteles, possibilita ter uma visão de que seu pensamento ainda pode contribuir para os dias de hoje, para que indivíduo fique integrado em sua comunidade ético-política, para que a singularidade de cada um seja considerada em consonância com o bem comum dos demais cidadãos.

\section{REFERÊNCIAS}

ARISTOTLE. Nicomachean ethics. Tradução de David Ross. London: Batoche Books, Kitchener, 1999.

ARISTÓTELES. Ética a Nicômaco. Tradução de Torrieri Guimarães. São Paulo: M. Claret, 2012.

BURNYEAT, M. Aprender a ser bom segundo Aristóteles: sobre a ética nicomaquéia de Aristóteles: textos selecionados. Coordenação de Marco Zingano. São Paulo: Odysseus, 2010.

CECCARELLI, P. R. A contribuição da psicopatologia fundamental para a saúde mental. Revista Latino Americana de Psicopatologia Fundamental, São Paulo, v. 6, n. 1, p. 13-25, $2003 . \quad$ https://doi.org/10.1590/141547142003001002

IRWIN, T. H. A felicidade permanente: Aristóteles e Sólon: sobre a ética nicomaquéia de Aristóteles: textos selecionados. Coordenação de Marco Zingano. São Paulo: Odysseus, 2010.

MCDOWELL, J. Questões da psicologia moral aristotélica: sobre a ética nicomaquéia de Aristóteles: textos selecionados. Coordenação de Marco Zingano. São Paulo: Odysseus, 2010.

ORTEGA, F. Genealogias da amizade. São Paulo: Iluminuras, 2002.

SONENREICH, Carol; ESTEVÃO, Giordano; SILVA FILHO, Luis de Morais Altenfelder. Notas sobre psicopatologia. Rev. Latinoam. Psicopat. Fund., v. 3, p. 124-145, 1999.

Recebido para publicação em 19/08/2016

Revisado em 22/08/2016

Aceito em 29/08/2016

\footnotetext{
3 Para justificar a diferença de concepção entre os gregos e modernos, em relação à noção da consciência de si via consciência do outro, Ortega (2002), recorre definição de Vernant (1986) que os Gregos como tinham sobre o "eu" como um "campo aberto de forças" (ORTEGA, 2002, p.42). Já em Aristóteles há breves passagens que situa a consciência do amigo por meio da percepção de si mesmo em Ética a Eudemo, Magna Moralia e Ética a Nicômaco.
} 